beneficial in their case, proof of this is lacking, and objective data are needed before such a suggestion can be made.

Peter L Grossman JACK S REMINGTON

Division of Infectious Diseases,

Department of Medicine,

Stanford University School of

Medicine and Division of Allergy,

Immunology and Infectious

Diseases,

alo Alto Medical Research

Palo Alto, California 94301,

' Remington, J S, Bulletin of the New York Academy of Medicine, 1974, 50, 211.

Garin, J P, Perrin-Fayolle, M, and Paliard, P, Presse

Médicale, $1965,73,531$.
Eyles, D E, and Coleman. N, Antibiotics and Chemotherapy, 1954, 4, 988 . Freireich, E J, et al, Cancer Chemotherapy Reports,
1966, 50, 219.

\section{Output of doctors}

SIR,-In your leading article "Making better use of our nurses" (21 May, p 1306) you again refer to fears of overproduction of doctors and conclude with the comment that "we need to start cutting the intake to our medical schools now."

Additional help from nurses or others is one of the many imponderables in a future situation that needs to be monitored continuously by "a proper statistical department." "If we had had such a department seven years ago, this mess would never have occurred and it must never be allowed to occur again." Among the other quantitatively unknown factors is the thought that "if doctors in this country were to work twice as hard as they do there would be 20000 doctors redundant; if they worked half as hard as they do another 20000 doctors would be required." Then there is the allimportant question of how future doctors are to be absorbed into the system at various levels and in various places to do the work currently undertaken by many overseas doctors, who are "not here for postgraduate training" but "to provide pairs of hands in the rottenest, worst hospitals in the country, because there is nobody else to do it."

The letter from Mr P Dawson-Edwards and Dr M E H Barrow (11 June, p 1531) highlights some of the distributional problems and illustrates the plight of many hospitals which are by no means the rottenest in the land. Manpower policies which encourage consultant growth in proportion to availability of eligible senior registrars are superficially reasonable, and will be strongly urged by those caught up in a potential log-jam, but the consequent attempted expansion of surgical services without support from anaesthetists, radiologists, and others can end only in disaster.

An analysis of the situation strongly suggests that if we cut down the numbers of medical students now we shall be condemning ourselves to a situation in which future growth in the numbers of practising doctors will be impossible for at least a decade; the total stock during this time might quite easily fall. Even without any expansion in the number of practising doctors we need all the graduates we have planned to produce in order to make any significant difference to our dependence on overseas doctors. As Dr C F Scurr (p 1531) points out, we must have a policy either of maintaining a sufficient output of British graduates or of allowing uncontrolled entry from overseas; we cannot sustain both and it is equally sure that we cannot do without both

The basis for these statements cannot be se out in a letter, but would need a short article. The quotations, incidentally, are all from noble contributors' ${ }^{1}$ to the House of Lords debate in 1961 on the situation that followed the Willink Committee's recommendations.

JAMES PARKhouse

Department of Anaesthetics,
University of Manchester

' Hansard (House of Lords), Fifth Series, vol 235, Session 1961-2, cols 1131-1209.

\section{Shortage of anaesthetists}

SIR,-Safe surgery depends on many details, but the unconscious security of anaesthesia is an essential one. British anaesthetists have and do lead the world in this observation and control of the many vital functions. It is no wonder they are offered rank and riches elsewhere in the world. Although I am unfamilia with any administrative problems they describe, Mr Paul Dawson-Edwards and D Michael Barrow (11 June, p 1531) are justified and correct to draw attention to a lack of anaesthetic service. Areas of excellence always develop restricted portals of entry. The examinations proving adequacy are of high order, and if all those who fulfil these criteria practise anaesthesia in this country they will not satisfy the need. There will not be a reduction in this standard of selection, so other methods must be sought. Medical students and hospital residents must have exposure and training in this essential service. There are many genera practitioners who would enjoy and benefit the service and themselves by part-time anaesthetic work. Perhaps part of the work of a consultant anaesthetist should be to oversee a number of anaesthetics in progress by others. Such adjustments alone will not cure the problems, however. The hospital service must show the pragmatism of reality over the impact of human suffering and reward for its relief. Not even the apparently enlightened principle of the greatest good for the greatest number can excuse indifference to individual suffering words of that idealist of national health Aneurin Bevan.

Perhaps all employed people of this country should pay compulsory insurance premiums for themselves and their families, the State's contribution being freedom of tax of such contribution and the payment for those not so insured. All patients would then be personal to those treating them. All consultant contracts should be personal and short-term, reflecting worth and endeavour. The aim and policy should be a streamlined excellent health service in which individual suffering receives individual care and remuneration.

JaCk SMaLI

Birmingham

SIR,-No one can feel satisfied with the present trends in the National Health Service and I certainly share some of the views expressed by the Birmingham consultants (11 June, $p$ 1531) about the state of affairs which has developed in the whole field of hospital medicine. However, I feel that the surgeons have adopted a rather defeatist attitude and have been unduly influenced by the tendency of the anaesthetists to assert their indispensibility. There should be no need to be restricted to a "simple emergency service," and if there are to be empty beds, as predicted, these could surely be used for the many patients requiring routine cold surgery.

When I retired four years ago after a professional lifetime in neurosurgery I went to West Africa (Côte d'Ivoire) to serve in a mission hospital, where I was the only surgeon on the staff. Almost the entire practice was general surgery. The majority of operations were carried out under local (or regional block) anaesthesia and most were done as day cases. The work included numerous cases of hernia, in which on several occasions resection of small intestine was necessary. This was done under the existing analgesia without further supplement. Conditions requiring a higher level of anaesthesia, such as hysterectomy or prostatectomy, were done under spinal anaesthesia, which I used nearly 100 times in 12 months.

Earlier this year Nicholls ${ }^{1}$ advocated the use of local anaesthesia for hernia operations, and he has not been alone in this respect. By an interesting coincidence in the same journal Glendenning ${ }^{2}$ extolled the advantages of day surgery.

Could not the surgeons of Birmingham (and elsewhere) use a little more imagination and enterprise, and overcome the frustrations generated by the present climate in the Health Service. They could find that, even with the current regrettable shortage of anaesthetists, a busy and rewarding surgical practice can be continued.

Charles Langmaid

Cardiff

Nicholls, J C, Annals of the Royal College of Surgeon

of England, 1977, 59, 124 .
Glendenning, D E H, Annals of the Royal College of Surgeons of England, 1977, 59, 104.

SIR,-We wish to support very strongly the opinion expressed by Mr P Dawson-Edward and $\operatorname{Dr} M$ Barrow (11 June, $p$ 1531). They have highlighted in a most effective manner the escalating tragedy of the hospital service. Our experience in Blackburn confirms all the conclusions and implications to be drawn from their letter: among other things, the increasingly adverse conditions under which hospital staff work and the Gilbertian state of affairs in the progress from junior to senio rank with its consequent lowering of morale, which is reflected in a disastrous decline in the effectiveness of the whole service.

We agree with $\mathrm{Mr}$ Dawson-Edwards and Dr Barrow that the greatest factor at the moment is the lack of incentive to achieve consultant status. This is most acutely felt in the so-called "shortage specialties" such as anaesthesia, radiology, and geriatrics but is by no means confined to them. It is clear that without adequate staffing of all specialist services the whole of the hospital service is even now grinding to a halt. Birmingham is only one case in point.

To expect consultants to continue to breach the ever-increasing gaps out of sheer altruism, especially in the light of the persistent and callous erosion of their status, is a hope which may still be fondly cherished in some quarters, but we doubt if the younger generation of consultants at least are likely to accept this situation for very much longer. We firmly believe that the standard of any hospital is only as good as that of its consultants. Consultants set the tone which is reflected all around them. 